\title{
Tesla Coil Theoretical Model and its Experimental Verification
}

\author{
Janis Voitkans (Researcher, Riga Technical University), Arnis Voitkans (Researcher, University of Latvia)
}

\begin{abstract}
In this paper a theoretical model of Tesla coil operation is proposed. Tesla coil is described as a long line with distributed parameters in a single-wire form, where the line voltage is measured across electrically neutral space. By applying the principle of equivalence of single-wire and two-wire schemes an equivalent two-wire scheme can be found for a single-wire scheme and the already known long line theory can be applied to the Tesla coil. A new method of multiple reflections is developed to characterize a signal in a long line. Formulas for calculation of voltage in Tesla coil by coordinate and calculation of resonance frequencies are proposed. The theoretical calculations are verified experimentally. Resonance frequencies of Tesla coil are measured and voltage standing wave characteristics are obtained for different output capacities in the single-wire mode. Wave resistance and phase coefficient of Tesla coil is obtained. Experimental measurements show good compliance with the proposed theory. The formulas obtained in this paper are also usable for a regular two-wire long line with distributed parameters.
\end{abstract}

Keywords - Transformers; Resonance; Transmission lines; Mathematical model; Electromagnetic modeling.

\section{INTRODUCTION}

Tesla transformer is a device which is used for obtaining high voltage. It was invented by genial Serbian scientist Nikola Tesla. The importance of his works in science and technology can scarcely be overestimated. Many of N. Tesla's discoveries so far passed ahead their time, that only today we can fully assess their essence, but some of them are still waiting for their time, for example, wireless transfer of energy along large distances. However, the operating principles of Tesla transformer have not been sufficiently explained and the model of operation that would describe physical processes in Tesla coil has not been created. It is very difficult to design Tesla coil and to predict its necessary properties and parameters. The design of Tesla transformer is shown in Fig. 1(a).

It consists of a primary winding $L_{1}$ with a small number of turns which is operated by a generator. The operating currents of this winding can be relatively high as it is wound with increased diameter wire. The secondary winding (Tesla coil) $L_{2}$ consists of much more turns which are wound with a small diameter wire usually in one layer. The upper terminal of the winding $L_{2}$ is connected to the load, in this case spatial capacitance $C$ (conducting sphere, hemisphere, ellipsoid, it may also be a load with two connectors). The Tesla coil $L_{2}$ lower terminal is connected either to ground or to the generator casing. In Fig. 1(b) Tesla autotransformer variant is shown. In this variant the upper terminal $L_{1}$ is connected with the lower one $L_{2}$. This construction allows slight increase of the output voltage.

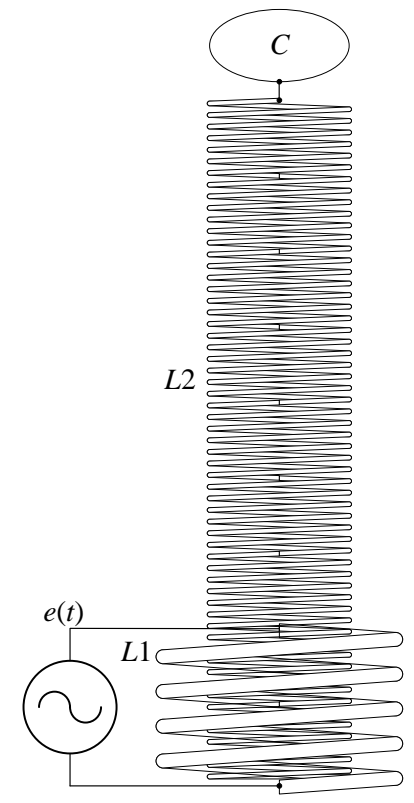

(a)

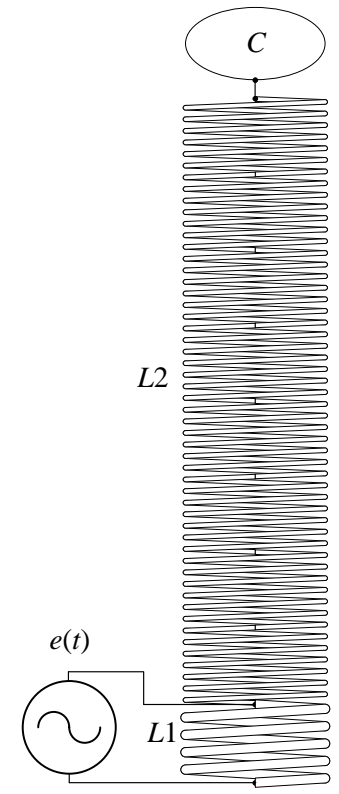

(b)
Fig. 1. Tesla transformer.

There are other Tesla transformer construction variations where $L_{2}$ is wound in a cone or like a flat spiral. The transformer size may vary from a few centimeters to a few tens of meters. The output voltage may be from a few tens to millions of volts. In experiments in Colorado Springs N. Tesla gained voltage of about $5 \cdot 10^{7}$ volts. The electrical voltage spatial distribution along the length of coil $l$ coordinate $x$ is shown in Fig. 2 .

In Fig. 2 we can observe that the voltage along the Tesla coil $L_{2}$ length coordinate is gradually increasing to maximum at its output.

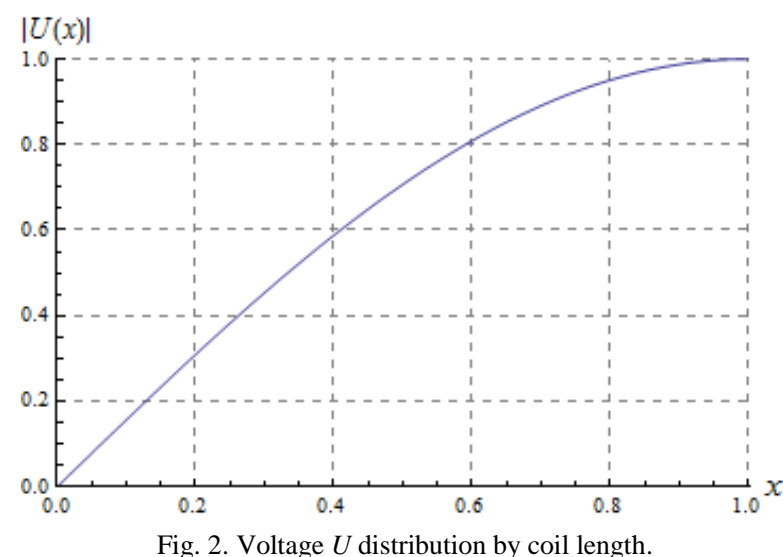

Fig. 2. Voltage $U$ distribution by coil length. 
The general transformer output voltage is proportional to the ratio of the number of turns of the secondary and primary winding. The output voltage of Tesla transformer does not correspond to this regularity, it is many times higher. To get high voltage at the output requires tuning it to a particular frequency which is called a working or resonance frequency. The anomalous voltage increase in output could be explained by occurring of series of electrical resonance in the secondary winding because this resonance is characterized by the voltage increasing across reactive elements by $Q$ times as compared to the input voltage, where $Q$ is contour Q-factor [1]. Nevertheless the attempts to describe the processes occurring in Tesla transformer in bounds of the voltage resonance theory have not yielded results [2], [3].

In this work the theoretical model of Tesla coil is presented and the comparison of theoretically acquired parameters with experimental measurements is performed.

\section{THEORETICAL MODEL OF TESLA COIL}

The proposed theoretical model assumes that the high voltage winding of Tesla transformer is operating in the mode of long line with distributed parameters with multiple reflections from coil terminals. The direct and reflected voltage and current waves are forming the mutual sum, which creates different standing wave sights by corresponding resonance frequencies.

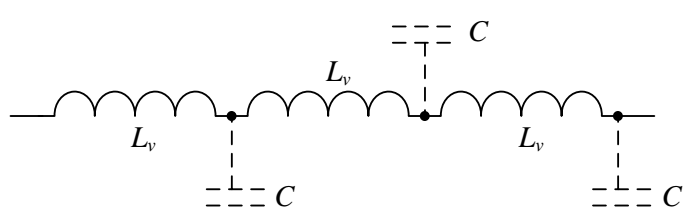

Fig. 3. Single wire equivalent scheme.

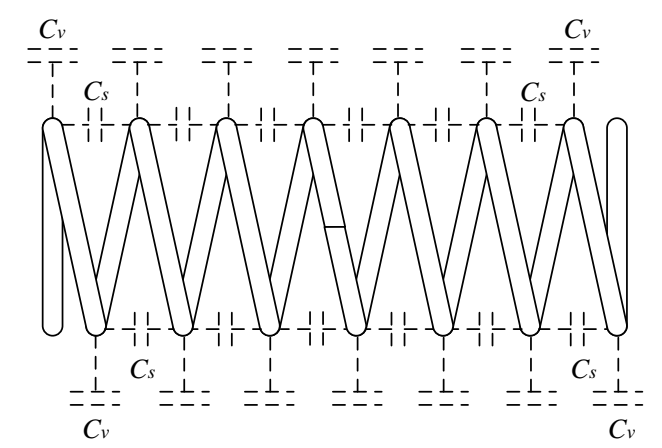

Fig. 4. Tesla coil winding scheme.

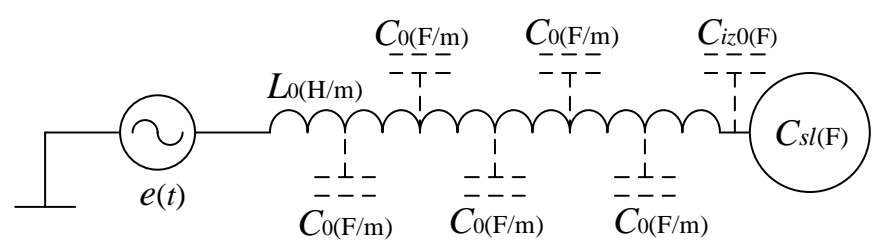

Fig. 5. Electrical scheme of Tesla coil model.
In this work Tesla transformer secondary coil operation is described as a long line in single wire electrical system format [4], [5], [6], where the circuit current is measured in accordance to infinitely distanced sphere (i.e., against neutral surrounding space). The equivalent scheme of the secondary winding consisting of an electric wire positioned in free space is shown in Fig. 3.

In the scheme (Fig. 3) $L_{V}$ is the straight wire inductivity per length unit (several micro-henries per meter), $C_{V}$ is wire selfcapacitance (capacitance against infinitely distant sphere) per length unit (approximately $5 \mathrm{pF} / \mathrm{m}$ ). $L_{V}$ and $C_{V}$ values depend on the length and diameter of the wire. Tesla coil wound of such a wire is shown in Fig. 4. In this case $L_{0}>L_{V}$, because there are several turns per length unit, and $C_{0}>C_{V}$ because additional inter-turn capacitance $C_{S}$ is introduced. $C_{S}$ depends on the distance and diameter of the turn positioned by the side.

As we are viewing Tesla coil as a single-wire long line with distributed parameters applying alternating input voltage, voltage and current travelling wave is introduced with multiple reflections from winding ends. At certain frequencies with different wave length resonance occurs.

In the theory of Tesla coil the processes occurring in Tesla coil can be described knowing its inductivity per length unit $L_{0}$ and winding self-capacitance per length unit $C_{0}$, resonance frequencies can be calculated, phase coefficient $\beta$, characteristic impedance $Z_{C}$ can be determined.

The electrical scheme of Tesla coil model (Fig. 5) consists of sinusoidal electrical voltage generator, where one terminal is connected to ground or other large spatial capacitance. Its output voltage is $U$ and frequency is $f$. To the output of a generator beginning of Tesla coil a winding with length $l$ and diameter $D$ is connected. The other terminal of the winding is connected to a spatial load capacitance $C_{s l}$ which together with the coil idle running capacitance $C_{i z 0}$ (Fig. 5) is forming a combined output capacitance $C_{i z}$. Any electrically conductive body with self-capacitance $C_{p}=C_{s l}$ can be a load capacitance. Spherical body has self-capacitance $C_{S}=4 \pi \varepsilon \varepsilon_{0} r$, where $r$ is sphere radius. It is possible to measure self-capacitance of a conductive body [8].

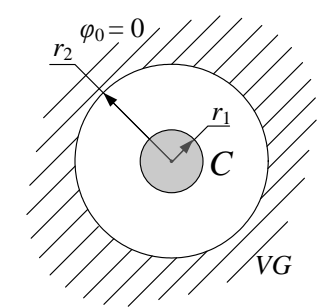

(a)

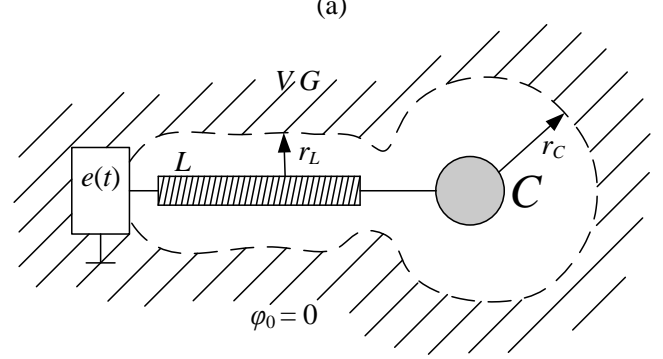

(b)

Fig. 6. Conductive body (a) and its virtual ground $V G$ (b). 
Main characteristics of Tesla winding are inductivity per length unit $L_{0}(\mathrm{H} / \mathrm{m})$ and capacitance per length unit $C_{0}(\mathrm{~F} / \mathrm{m})$.

\section{VIRTUAL GROUND OF SINGLE-WIRE SCHEME}

Any single-wire electrical scheme can be substituted with an equivalent two-wire scheme where virtual ground serves as a common connection. Its theoretical description and experimental verification is shown in work [7]. The existence of virtual ground is discovered theoretically by describing onewire schemes with Kirchhoff equations, where electrical capacitance and electrical potential of a conductive body is determined regarding to infinitely distant sphere. Illustration of virtual ground is shown in Fig. 6(a).

In Fig. 6(a) a spherical double-layer capacitor is shown where one electrode is in a free space placed spherical electrically conductive body $C$ with diameter $r_{1}$, which is centrically encased by spherical hollow electrode $V G$ with inner radius $r_{2}$. Electrical capacitance of such double-layer capacitor is expressed as

$$
C=\frac{4 \pi \varepsilon \varepsilon_{0} r_{1}}{1-r_{1} / r_{2}} .
$$

If radius $r_{2}$ tends toward infinity, which corresponds to infinitely remote sphere, as defined in electro-physics, with zero electrical potential $\left(\varphi_{0}=0\right)$, then the sphere with radius $r_{1}$ gains capacitance

$$
C=4 \pi \varepsilon_{0} r_{1},
$$

which is also called self-capacitance $C_{p}$ of a conductive body towards infinitely remote sphere. Electrical potential $\varphi_{c}$ of a body is determined regarding to a zero potential of this sphere, in this case

$$
U_{C}=\varphi_{C}-\varphi_{0}=\varphi_{C} .
$$

Nevertheless, current understanding of infinitely remote sphere in electro-physics creates problems for its practical use as it is difficult to understand how electrical force field lines could be completed as it is required by principle of continuity of electric current after passing infinite distance if electrical field propagates with limited speed (speed of light).

Is it possible to change something in our understanding of infinitely remote sphere? The answer is in formula (1). It turns out that the conductive body $C$ acquires a value close to its selfcapacitance $C_{p}$ if the radius of outer sphere $r_{2}$ gets only several tens of times larger than $r_{1}$. Five percent boundary is achieved when $r_{2} \cong 20 r_{1}$, but one percent difference of $C_{p}$ from selfcapacitance value is when $r_{2} \cong 100 r_{1}$. It can be concluded that the infinitely remote sphere is close to conductive body and it would be more understandable to call it a virtual ground $V G$ (Fig. 6).

For a complex configuration body like generator $e(t)$, shown in Fig. 6(b), series connection with coil $L$ and capacitance $C$ area of virtual ground $V G$ depends on linear dimensions of each separate component. As we can see in Fig. 6(b), the distance to the $V G$ boundary $r_{L}$ for the coil $L$ is smaller than $r_{C}$ for the sphere $C$ because the diameter of the coil is smaller than that of the sphere. The virtual ground is connected with a casing of the generator, because the displacement currents generated by the single-wire scheme capacities are connected to it.

Physically free, neutral space with a zero electrical potential serves as a virtual ground. The displacement currents created by self-capacitance of bodies which are proportional to the speed of change of electric field and capacitance value flow in it.

The $V G$ electrical resistance for displacement currents is close to zero. It is ensured by huge cross-section area of a virtual electric wire. Joule-Lance losses of $V G$ are close to zero too.

\section{Tesla CoIl EQuivalent Two-WIRE SCHEME}

As the one-wire connection electrical scheme (Fig. 5) is completely equivalent to the two-wire scheme (Fig. 7) and it corresponds to the traditional long line, the known theoretical description of long line with distributed parameters can be applied to the one-wire system [9].

Zero point of coordinate $x$ (Tesla coil beginning), direction of change and length of line $l$ (Tesla coil ending) is shown in Fig. 7.

To simplify calculations, capacitance as shown in Fig. 7, which is created by last turns of the coil and output, and load capacitance $C_{s l}$ are unified into one output capacitance $C_{i z}$. These capacities are connected in parallel, due to that $C_{i z}=C_{i z 0}+C_{s l}$.

The long line is considered homogenous and without losses. It is assumed that loss resistance per length unit $R_{0}=0$ and loss conductivity per length unit $G_{0}=0$. In the first approximation it may be done because Tesla coil Q-factor is large: $Q \gg 1$.

\section{DiRect And Reflected Voltage Wave IN Tesla CoIL}

When describing physical processes in Tesla coil (Fig. 5) and its equivalent scheme (Fig. 7) it is assumed that multiple voltage and current wave reflections are occurring. In addition to that coil ending matches idle running mode with a nature of capacitive load and beginning matches short circuit because generator $e(t)$ is connected to ground and its inner resistance $R_{i}$ is close to zero.

Generator $e(t)$ is a source of sinusoidal voltage with a frequency $f$ and amplitude $U_{m}$

$$
e(t)=U_{m} \sin (\omega t)
$$

where $\omega=2 \pi f$.

It is assumed that $e(t)$ is an ideal source of voltage, in this case inner resistance $R_{i}=0$ as for Tesla coil $R_{i}<<Z_{c}$.

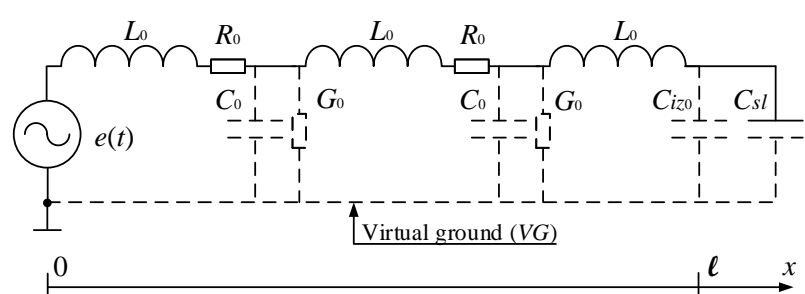

Fig. 7. Tesla coil equivalent two-wire scheme and coordinate reference system. 
The generator output voltage (3) in the long line induces a direct running-wave which is describable with two-argument function

$$
u(x, t)_{t}=U_{m} \sin (\omega t-\beta x),
$$

where $\beta$ is the phase coefficient.

The direct running-wave of the voltage propagates in axis $x$ direction until reaches the end of line

$$
u(l, t)_{t}=U_{m} \sin \left(\omega t-\beta l+\varphi_{i z}\right) .
$$

Phase offset angle $\varphi_{i z}$ value and sign is determined by the load. In case of capacitive load $\varphi_{i z}$ is negative and in case of inductive load $\varphi_{i z}$ is positive. While idle running, when $C_{i z}=0, \varphi_{i z}=0$ too.

Under the influence of an unbalanced load $\left(Z_{i z} \neq Z_{C}\right)$ wave is reflected and propagates in a direction of generator moving the same distance as the direct wave which depends on $\varphi_{i z}$ and $\beta$. Changing coordinate has to be counted off the end of the line, due to that $x$ has to be substituted by $(l-x)$. As a result we get a reflected wave

$$
u(x, t)_{a}=U_{m} \sin \left(\omega t-\beta(-x+2 l)+2 \varphi_{i z}\right) .
$$

Reflected voltage wave at the beginning of the coil where $x=0$ is

$$
u(0, t)_{a}=U_{m} \sin \left(\omega t-2 \beta l+2 \varphi_{i z}\right) .
$$

At this point wave is reflected again in the direction of the direct wave due to short circuit. Let us label it as $u(x, t)_{a t}$.

\section{CAlculation of Tesla CoIl LoAd Influence}

Angle $\varphi_{i z}$ that characterizes the influence of a load to a Tesla coil can be calculated using the complex reflection coefficient at the end of the line

$$
\tilde{N}=\frac{\dot{U}_{a}(l)}{\dot{U}_{t}(l)}=\frac{\tilde{Z}_{i z}-Z_{C}}{\tilde{Z}_{i z}+Z_{C}},
$$

where:

$\dot{U}_{t}(l)$ complex direct voltage at the output of a line;

$\dot{U}_{a}(l)$ complex reflected wave at the output of a line;

$Z_{C} \quad$ characteristic impedance;

$\tilde{Z}_{i z} \quad$ complex output impedance.

Inserting into the expression (8) the value of output impedance $\tilde{Z}_{i z}=-j /\left(\omega C_{i z}\right)$ we get

$$
\tilde{N}=\frac{1-j \omega C_{i z} Z_{C}}{1+j \omega C_{i z} Z_{C}} .
$$

Module of reflection coefficient is

$$
|\tilde{N}|=1 \text {. }
$$

Its phase $\varphi_{i z}$ can be expressed using sinus or tangents of $\tilde{N}$ but preference is given to $\arg (\tilde{N})$ function due to the fact that this function also respects the position of this angle in a quadrant

$$
2 \varphi_{i z}=\arg \frac{1-j \omega C_{i z} Z_{C}}{1+j \omega C_{i z} Z_{C}}
$$

and using (8) it can be expressed

$$
\dot{U}_{a}(l)=\dot{U}_{t}(l) \cdot e^{j 2 \varphi_{i z}} .
$$

There is a short circuit at the beginning of a line, $\tilde{N}=-1$ due to that. At this point there is no significance to a value of input capacitance because it is shunted by short-circuit which is created by the inner resistance of a generator which is close to zero. Wave resistance $Z_{C}$ value has a small significance, either. Hence at the $x=0$ coordinate a wave reflected in the direct direction is in an opposite phase with the falling wave

$$
\dot{U}_{a t}(0)=\dot{U}_{a}(0) \text {. }
$$

\section{TeSLA COIL AMPLITUdE-FREQUENCY CHARACTERISTIC}

Tesla coil is a resonance system with a high Q-factor $Q$. This coefficient shows how many times the output voltage is higher than the input voltage

$$
U_{i z}=Q U_{i e} .
$$

To make the determination of an amplitude-frequency characteristic of Tesla coil easier it is assumed that a voltage wave propagates in a line without losses, it is reflected $Q$ times without changing amplitude and then immediately disappears. As a result the output voltage will be increased $Q$ times which conforms to the reality. When $\mathrm{Q}$-factor of the coil $Q$ would change the resonance frequencies should also change slightly, but this approximation does not anticipate it. It should be considered a shortcoming of this method.

To get a Tesla coil amplitude-frequency characteristic a transition from two argument function to a single argument function is desirable. It is possible to get rid of the time dimension by transferring direct (4) and reflected (6) wave functions to the complex plane:

$$
\begin{gathered}
e(x, t)_{t} \Rightarrow \dot{U}_{t}=U_{m} \cdot e^{-j \beta x}, \\
e(x, t)_{a} \Rightarrow \dot{U}_{a}=U_{m} \cdot e^{j\left(-\beta(-x+2 l)+2 \varphi_{i z}\right)} .
\end{gathered}
$$

This transformation allows writing direct and reflected signals in a complex form as shown in the expressions (13) and (14). Direct wave in line

$$
\dot{U}_{t}(x)=U_{m} \cdot e^{-j \beta x} .
$$

Direct wave at the end of a line $x=l$ together with the influence of a load

$$
\dot{U}_{t}(l)=U_{m} \cdot e^{j\left(-\beta l+\varphi_{i z}\right)} .
$$

Reflected wave at the end of a line $x=l$, using (11)

$$
\dot{U}_{a}(l)=U_{m} \cdot e^{j\left(-\beta l+2 \varphi_{i z}\right)} .
$$

Reflected wave in a line $x \Rightarrow l-x$

$$
\dot{U}_{a}(x)=U_{m} \cdot e^{j\left(-\beta(-x+2 l)+2 \varphi_{i z}\right)} .
$$

Reflected wave at the beginning of a line

$$
\dot{U}_{a}(0)=U_{m} \cdot e^{j\left(-2 \beta l+2 \varphi_{i z}\right)} .
$$

It is reflected from the beginning of a line again as shown in (12) and becomes a reflected direct wave 


$$
\dot{U}_{a t}(0)=-U_{m} \cdot e^{j\left(-2 \beta l+2 \varphi_{i z}\right)} .
$$

Reflected direct wave at a current coordinate of a line

$$
\dot{U}_{1 a 1 t}(x)=-U_{m} \cdot e^{j\left(-\beta(x+2 l)+2 \varphi_{i z}\right)} .
$$

Similarly further direct and reflected waves can be found

$$
\begin{gathered}
\dot{U}_{1 t 2 a}(x)=-U_{m} \cdot e^{j\left(-\beta(-x+4 l)+4 \varphi_{i z}\right)}, \\
\dot{U}_{2 a 2 t}(x)=U_{m} \cdot e^{j\left(-\beta(x+4 l)+4 \varphi_{i z}\right)}, \\
\dot{U}_{2 t 3 a}(x)=U_{m} \cdot e^{j\left(-\beta(-x+6 l)+6 \varphi_{i z}\right)}, \\
\dot{U}_{3 a 3 t}(x)=-U_{m} \cdot e^{j\left(-\beta(x+6 l)+6 \varphi_{i z}\right)},
\end{gathered}
$$

and similarly further $Q$ times.

If $Q=64$ the last reflected wave in a line is

$$
\dot{U}_{31 t 32 a}(x)=-U_{m} \cdot e^{j\left(-\beta(-x+64 l)+64 \varphi_{i z}\right)} .
$$

It is beneficial to choose Q-factor of a coil equal to $4 n$ where $n$ is a natural number starting with 1 , because in this case an analytical function of sum of different waves can be easily found. As an example a total voltage in a coil with $n=16$ which corresponds to $Q=64$ is shown

$$
\dot{U}_{64}(x)=\dot{U}_{t}(x)+\dot{U}_{a}(x)+\dot{U}_{1 a 1 t}(x)+\ldots+\dot{U}_{31 t 31 a}(x) \text {. }
$$

Inserting into expression (15) corresponding direct and reflected waves and summing them by pairs, after simplification, an expression is obtained

$$
\begin{aligned}
& \dot{U}_{64}(x)=4 U_{m} \times \csc \left(2\left(\beta l-\varphi_{i z}\right)\right) \times \sin \left(\beta l-\varphi_{i z}\right) \times \\
& \left.\times \sin \left(32\left(\beta l-\varphi_{i z}\right)\right) \times \cos \left(\beta(l-x)-\varphi_{i z}\right)\right) \times j e^{-32 j\left(\beta l-\varphi_{i z}\right)} .
\end{aligned}
$$

Multiplier $j e^{-32 j\left(\beta l+\varphi_{i z}\right)}$ corresponds to the time function

$$
\cos \left(\omega t-32\left(\beta l-\varphi_{i z}\right)\right) \text {. }
$$

It can be observed that cosine (17) argument $\omega t-32\left(\beta l-\varphi_{i z}\right)$ does not anymore depend on coordinate $x$. That means that a standing wave has formed in a line, but the rest part of the expression (16)

$\dot{U}_{64}(x)=4 U_{m} \times \csc \left(2\left(\beta l-\varphi_{i z}\right)\right) \times \sin \left(\beta l-\varphi_{i z}\right) \times$

$\left.\times \sin \left(32\left(\beta l-\varphi_{i z}\right)\right) \times \cos \left(\beta(l-x)-\varphi_{i z}\right)\right)$

shows an amplitude of the standing wave in a dependence on coordinate $x$. Expression (16) in a general way for different values of Q-factor can be written as

$\dot{U}_{Q}(x)=4 U_{m} \times \csc \left(2\left(\beta l-\varphi_{i z}\right)\right) \times \sin \left(\beta l-\varphi_{i z}\right) \times$

$\left.\times \sin \left(\frac{\left(\beta l-\varphi_{i z}\right) Q}{2}\right) \times \cos \left(\beta(l-x)-\varphi_{i z}\right)\right) \times j e^{\frac{-j\left(\beta l-\varphi_{i z}\right) Q}{2}}$,

at $Q / 4=n$, where $n$ is a natural number $1,2,3, \ldots$

Using (19) voltage for a line with other $Q=4 n$ can be written. For example, if $n=25$ then Q-factor of the coil is $Q=100$ and the following expression is obtained:
$\dot{U}_{100}(x)=4 U_{m} \times \csc \left(2\left(\beta l-\varphi_{i z}\right)\right) \times \sin \left(\beta l-\varphi_{i z}\right) \times$

$\left.\times \sin \left(50\left(\beta l-\varphi_{i z}\right)\right) \times \cos \left(\beta(l-x)-\varphi_{i z}\right)\right) \times j e^{-50 j\left(\beta l-\varphi_{i z}\right)}$.

It is not allowed to use Q-factor of a coil $Q=98$ in formula (19) because in this case $Q / 4=24.5$ and it is not a natural number.

If $n=1$ is inserted in the expression (19) and it is simplified, a four wave summary voltage $\dot{U}_{4}(x)$ which corresponds to Q-factor $Q=4$ is obtained:

$\dot{U}_{4}(x)=4 U_{m} \times \sin \left(\beta l-\varphi_{i z}\right) \times$

$\left.\times \cos \left(\beta(l-x)-\varphi_{i z}\right)\right) \times j e^{-2 j\left(\beta l-\varphi_{i z}\right)}$.

$Q=4$ is the smallest allowed value that is usable in formula (19). There is no upper limit for the natural number $n$.

Inserting into the equation (18) $x=l$, phase coefficient $\beta=2 \pi f \sqrt{L_{0} C_{0}}$, substituting angle $\varphi_{\mathrm{iz}}$ by the formula (10), taking $Z_{C}=\sqrt{L_{0} / C_{0}}$ and applying module to $U_{64}(x)$, an expression for the Tesla coil amplitude-frequency characteristic at the end of a line when $Q=64$ is obtained.

$$
\begin{aligned}
& \left|U_{64}(f)\right|=\mid \csc \left(2\left(2 \pi f l \sqrt{L_{0} C_{0}}-\varphi_{i z}\right)\right) \times \\
& \times \sin \left(2 \pi f l \sqrt{L_{0} C_{0}}-\varphi_{i z}\right) \times \\
& \times \cos \left(\varphi_{i z}\right) \times \sin \left(32\left(2 \pi f l \sqrt{L_{0} C_{0}-\varphi_{i z}}\right)\right) \mid,
\end{aligned}
$$

where

$$
\varphi_{i z}=\frac{1}{2} \arg \frac{1-j 2 \pi f C_{i z} \sqrt{L_{0} / C_{0}}}{1+j 2 \pi f C_{i z} \sqrt{L_{0} / C_{0}}} .
$$

In Fig. 8 an example of amplitude-frequency characteristic $\left|U_{64}(f)\right|$ with values $U_{m}=10 \mathrm{~V}, l=0.8 \mathrm{~m}, L_{0}=2.2 \mathrm{mH} / \mathrm{m}$, $C_{0}=20 \mathrm{pF} / \mathrm{m}, C_{i z}=1 \mathrm{pF}$ is shown.

In Fig. 8 it can be observed that at increasing frequency resonance output voltage decreases, it happens due to increasing phase shift $\varphi_{\mathrm{iz}}$ which is caused by output capacitance $C_{i z}$. At frequencies between base resonances micro resonances with small amplitude are being formed, these can be considered as a background voltage in a coil.

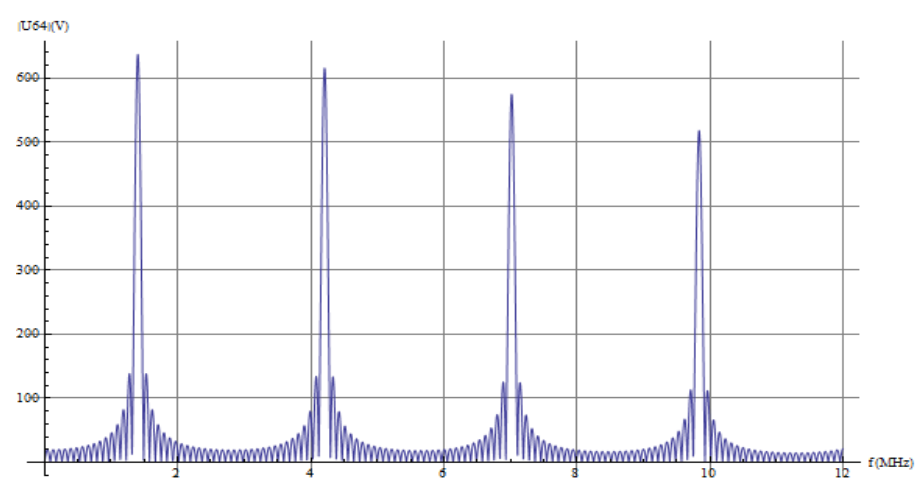

Fig. 8. Tesla coil amplitude-frequency characteristic. 


\section{DETERMinAtion OF TESLA CoIl Resonance FREQUENCIES}

Differentiating voltage amplitude multiplier in the expression (19) by variable $\beta$ and equalizing this derivative with zero its frequencies of voltage maximum in a line can be calculated. To avoid an influence of micro maximums it is advisable to use the multiplier of the four wave variation $\dot{U}_{4}(x)$ (21) of the expression (19)

$$
U_{4}(x)=4 U_{m} \times \sin \left(\beta l-\varphi_{i z}\right) \times \cos \left(\beta(l-x)-\varphi_{i z}\right)
$$

by substituting $x$ with line end coordinate $x=l$.

Deriving by variable $\beta$ and equalizing it with zero, an expression is obtained

$$
\cos \left(\beta l-\varphi_{i z}\right)=0 \text { and } \beta l+\varphi_{i z}=\pi / 2+n \pi
$$

where $n=0,1,2,3 \ldots$

Inserting into (24) expression $\beta=\omega \sqrt{L_{0} C_{0}}$ and solving it in respect to $\omega$, resonance frequencies are obtained

$$
\omega_{n}=\frac{\pi(2 n+1)+2 \varphi_{i z}}{2 l \sqrt{L_{0} C_{0}}} .
$$

For example, for a quarter wave resonance $n=0$ :

$$
\omega_{n}=\frac{\pi+2 \varphi_{i z}}{2 l \sqrt{L_{0} C_{0}}} .
$$

For wave resonance $n=1$ and its angular frequency is

$$
\omega_{n}=\frac{3 \pi+2 \varphi_{i z}}{2 l \sqrt{L_{0} C_{0}}} .
$$

Similarly resonance angular frequencies for other waves can be found.

\section{Tesla CoIl Standing Wave Calculation}

To acquire standing wave sight amplitude multiplier of the expression (19), which depends on coordinate $x$, can be used and maximum voltage in a line can be normalized. As a result normalized voltage is obtained, it is necessary to take the module of it:

$$
\left|U_{N}(x)\right|=\left|\cos \left(\beta(l-x)-\varphi_{i z}\right)\right| .
$$

Using the expression (28) and normalizing it to the length unit $l$ a voltage distribution in a homogenous line without losses can be obtained. The value of the phase coefficient $\beta$ has to be such that a corresponding wave resonance would set in Tesla coil. Standing wave sight for a quarter wave resonance is shown in Fig. 2.

In Fig. 9 voltage distribution examples for $3 \lambda / 4$ (Fig. 9(a))

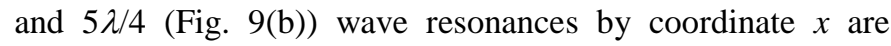
shown. Output of the coil is loaded by electrically conductive sphere with a diameter $D=39.4 \mathrm{~mm}$ and self-capacitance $C_{p}=C_{s l}=2.19 \mathrm{pF}$. Output idle-load capacitance which is created by last windings of the coil and coil output terminal is approximately $C_{i z 0}=1 \mathrm{pF}$. Summary output capacitance $C_{i z}=C_{i z 0}+C_{s l}=3.19 \mathrm{pF}$.

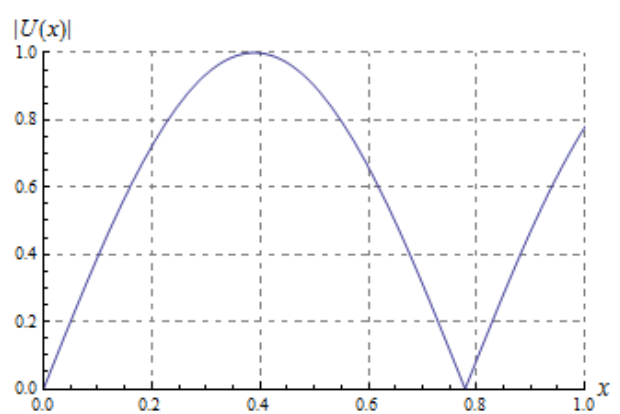

(a)

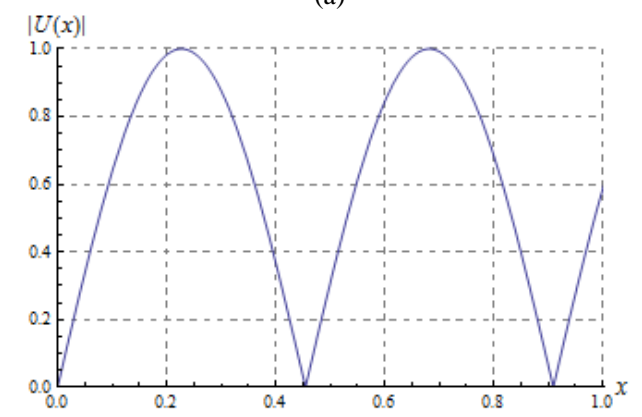

(b)

Fig. 9. Voltage distribution in Tesla coil for (a) $3 \lambda / 4$ and (b) $5 \lambda / 4$ wave resonances.

In idle load mode when $\varphi_{\mathrm{iz}}=0$ maximal voltage of a line $U_{\max }$ is equal to both all half waves, and output quarter wave. If there is a reactive load at the output of a coil $U_{i z}<U_{\max }$.

In the case of a capacitive load voltage minimum point coordinate $x_{0}$ moves closer to the load and output quarter wave gets shorter, i.e., gets smaller than $\lambda / 4$, but in the case of inductive load coordinate $x_{0}$ moves away from the load and output quarter wave gets longer than $\lambda / 4$.

\section{DETERMINATION OF LOAD INDUCED ANGLE $\varphi_{\mathrm{IZ}} \mathrm{IF}$ STANDING WAVE DISTRIBUTION IS KNOWN}

If the closest to a load minimum coordinate $x_{0}$ and number of whole half waves in a coil $n$ are known $\varphi_{i z}$ value can be calculated equaling the expression (28) to zero:

$$
\left|\cos \left(\beta\left(l-x_{0}\right)-\varphi_{i z}\right)\right|=0
$$

Physically a corresponding solution of this equation is

$$
\varphi_{i z}=\beta\left(l-x_{0}\right)-\pi / 2 .
$$

By substitution of $\beta=2 \pi / \lambda$ and $\lambda=2 x_{0} / n$ into the equation (29) it can be obtained

$$
\varphi_{i z n}=\pi\left(n\left(\frac{l}{x_{0}}-1\right)-\frac{1}{2}\right),
$$

which is usable both with capacitive and inductive loads in the case when $n=1,2,3 \ldots$ is a natural number of full half waves in Tesla coil.

If $n=1$, the equation (30) gives $\varphi_{i z}=0$ at $x_{0}=2 l / 3$ that corresponds to idle-load of a long line. If $n=2$, idle-load mode corresponds to coordinate. Formula (30) is not applicable to quarter wave resonance because it gives undetermined state $\left(n=1\right.$ and $\left.x_{0}=0\right)$. For this resonance $\varphi_{i z}$ has to be determined by other means. 


\section{DETERMINATION OF LOAD INDUCED PHASE SHIFT FOR QUARTER WAVE RESONANCE}

To determine angle $\varphi_{i z 0}$ in a quarter wave resonance it is necessary to know the angle frequency $\omega_{0}$ of this resonance, the three quarters resonance frequency $\omega_{1}$ and its $\varphi_{i z 1}$.

Determining $\cos \left(\varphi_{i z 1}\right)$ from the expression (9) and writing it for two first resonances an equation system is obtained

$$
\left\{\begin{array}{l}
\cos \left(2 \varphi_{i z 0}\right)=\frac{1-\omega_{0}^{2}\left(C_{i z} Z_{C}\right)^{2}}{1+\omega_{0}^{2}\left(C_{i z} Z_{C}\right)^{2}} \\
\cos \left(2 \varphi_{i z 1}\right)=\frac{1-\omega_{1}^{2}\left(C_{i z} Z_{C}\right)^{2}}{1+\omega_{1}^{2}\left(C_{i z} Z_{C}\right)^{2}},
\end{array}\right.
$$

which is solved in respect to unknowns $\varphi_{i z 0}$ and $C_{i z} Z_{C}$. As a result the product of output capacitance and wave resistance

$$
C_{i z} Z_{C}=\frac{\left|\tan \left(-\varphi_{i z 1}\right)\right|}{\omega_{1}}
$$

and the load induced phase shift for quarter wave resonance $\varphi_{i z 0}$ are obtained

$\varphi_{i z 0}=-\arccos \frac{\omega_{1}^{2}-\omega_{0}^{2}+\left(\omega_{1}^{2}+\omega_{0}^{2}\right) \cos \left(2 \varphi_{i z 1}\right)}{\omega_{1}^{2}+\omega_{0}^{2}+\left(\omega_{1}^{2}-\omega_{0}^{2}\right) \cos \left(2 \varphi_{i z 1}\right)}$.

If approximated angle $\varphi_{i z 0}$ may be calculated easier. As resistance of capacitive output is inversely proportional to frequency $x_{i z C}=1 /\left(\omega C_{i z}\right)$, knowing the voltage shift angle introduced by coil output reactivity at one frequency it can be proportionally calculated for other frequency, therefore

$$
\varphi_{i z 0}=\varphi_{i z 1}\left(\omega_{0} / \omega_{1}\right) .
$$

Equation (34) gives a result which is approximately by $5 \%$ different comparing with formula (33).

Knowing the quarter wave resonance $\varphi_{i z 0}$, its wave length $\lambda_{0}$ can be calculated that is not obtainable from standing wave sight. In order to do it, it is necessary to find at what coordinate $x_{m}$ voltage $\dot{U}(x)$ reaches maximum, equation (28) has to be derived by $x$, substituted by $\beta=2 \pi / \lambda_{0}$ and $x_{m}=\lambda_{0} / 4$, as well as equalized to zero. Expressing the quarter wave resonance wave length $\lambda_{0}$ from the obtained equation we get:

$$
\lambda_{0}=\frac{4 l \pi}{2 \varphi_{i z 0}+\pi} .
$$

Formula (35) shows that in the case of negative $\varphi_{i z}$ the quarter wave $\lambda_{0} / 4$ is higher than a coil length $l$.

\section{TESLA COIL AS A LONG LINE EXPERIMENTAL RESEARCH}

Experimental scheme for Tesla coil research is shown in Fig. 10. In a one layer wound as one-wire connection Tesla coil is attached to the voltage generator $\Gamma-112 \mathrm{~A}$ output (Fig. 5). Diameter of the coil is $D_{S}=1.8 \mathrm{~cm}$, length $l=80 \mathrm{~cm}$, diameter of enameled wire including isolation $D_{V}=0.30 \mathrm{~mm}$, number of turns $n \approx 2600$.

Tesla coil inductivity if measured with alternating current bridge E7-8 at frequency $f=1 \mathrm{kHz}$ is $L=1.76 \mathrm{mH}$ that means $L_{0}=2.2 \mathrm{mH}$.

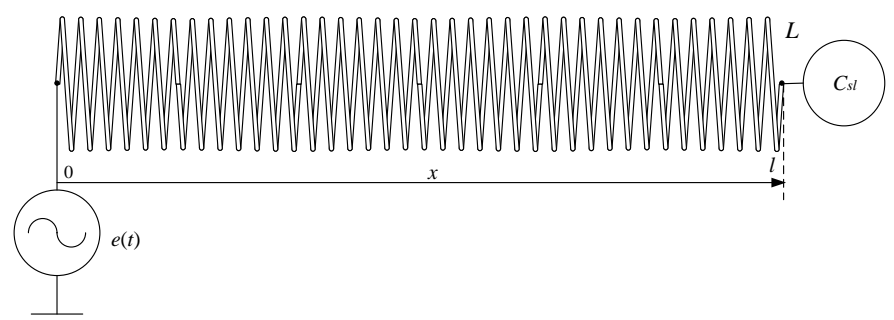

Fig. 10. Scheme of the experiment.

In the experiments when load capacitance is required different diameter metallic balls or cylindrical bars that are attached to coil output with an approximately $5 \mathrm{~cm}$ long wire are used. In measurements without load connection output wire remains and together with the last turn form an idle-load output capacitance $C_{i z 0}$ of the coil.

Electrical field intensity distribution close to Tesla coil is registered either with a neon lamp by observing the intensity of its glow or by voltage induced in an oscilloscope probe, which has high input resistance.

Measurements are performed both when load is not connected, and with electrically conductive spheres with diameter $D_{C 1}=39.4$ $\mathrm{mm}$ and $D_{C 2}=65 \mathrm{~mm}$ connected to coil output. Self-capacities of these spheres are $C_{s l 1}=2.19 \mathrm{pF}$ and $C_{s l 2}=3.62 \mathrm{pF}$. The length of the connection wire is approximately $5 \mathrm{~cm}$.

During the experiments different resonance frequencies $f_{n}$ are measured and standing wave characteristics for each of them are registered. The results of the measurements are shown in Table I. The voltage knot point coordinates are labelled with $x_{n m}$, where $n$ is resonance sequence number, $m$ is knot sequence number starting from the closest to the load.

Resonances also occur at higher frequencies but their voltage level is low and qualitative measurements are difficult to perform. From the measurement results it can be observed that under the influence of load capacitance $C_{s l}$ resonance frequencies slightly decrease and voltage knot points move closer to the end of the line.

Using standing wave knot coordinates it is possible to verify if the line is homogenous by comparing number of half waves of one standing wave sight with the maximum number of half waves. When the load is not connected for a $7 \lambda / 4$ resonance number of whole half waves in the coil $n=3$ and their lengths are show in Table I, where

$$
\begin{aligned}
& 1 / 2 \lambda_{3}^{\prime}=x_{32}-0=24.5 \mathrm{~cm}, \\
& 1 / 2 \lambda_{3}^{\prime \prime}=x_{31}-x_{32}=22 \mathrm{~cm}, \\
& 1 / 2 \lambda_{3}^{\prime \prime \prime}=x_{30}-x_{31}=26 \mathrm{~cm} .
\end{aligned}
$$

Comparing different half wave lengths in different Tesla coil regions it can be observed that they are different. That means phase coefficient $\beta$ and characteristic impedance $Z_{C}$ depend on the coordinate of the long line. It can be concluded that the basic parameters of the line $L_{0}$ and $C_{0}$ are also changing. At the ends of the coil half wave lengths increase, therefore $L_{0}, C_{0}$ and $\beta$ decrease. Magnetic field at the centre of the coil is homogenous. Therefore inductivity by length unit $L_{0}$ is the highest. By getting closer to the ends of the coil magnetic field starts to scatter and $L_{0}$ is decreasing. 
TABLE I

RESULTS OF MEASUREMENTS

\begin{tabular}{|l|l|l|l|l|l|}
\hline $\begin{array}{c}\text { Sphere D } \\
C_{s l}\end{array}$ & Wave type & $\lambda / 4$ & $3 \lambda / 4$ & $5 \lambda / 4$ & $7 \lambda / 4$ \\
\hline $0 \mathrm{~mm}$ & Frequency, MHz & $f_{0}=1.635$ & $f_{1}=4.525$ & $f_{2}=7.036$ & $f_{3}=9.266$ \\
\cline { 2 - 6 } $0 \mathrm{pF}$ & $\begin{array}{c}\text { Knot point } \\
\text { coordinates, cm }\end{array}$ & - & $x_{10}=57$ & $\begin{array}{c}x_{20}=67.5 \\
x_{21}=34\end{array}$ & $\begin{array}{l}x_{30}=72.5 \\
x_{31}=46.5 \\
x_{32}=24.5\end{array}$ \\
\hline $39.4 \mathrm{~mm}$ & Frequency, MHz & $f_{0}=1.473$ & $f_{1}=4.156$ & $f_{2}=6.633$ & $f_{3}=8.836$ \\
\cline { 2 - 6 } $2.19 \mathrm{pF}$ & Knot point & - & $x_{10}=63$ & $x_{20}=73.5$ & $x_{30}=77.5$ \\
& coordinates, cm & & & $x_{21}=36.6$ & $x_{31}=49.5$ \\
& & & $f_{1}=3.977$ & $f_{2}=6.478$ & $f_{32}=8.717$ \\
\hline $65 \mathrm{~mm}$ & Frequency, $\mathrm{MHz}$ & $f_{0}=1.362$ & $x_{10}=66.5$ & $x_{20}=76.5$ & $x_{30}=78.5$ \\
\cline { 2 - 6 } $3.62 \mathrm{pF}$ & Knot point & - & & $x_{21}=38$ & $x_{31}=50.5$ \\
& coordinates, cm & & & $x_{32}=26.5$ \\
\hline
\end{tabular}

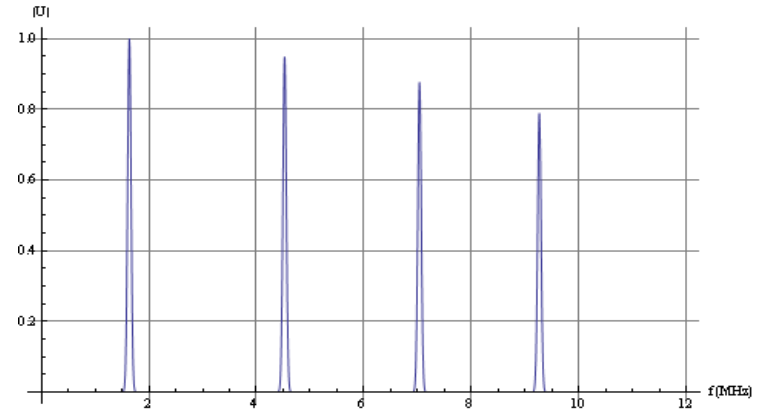

Fig. 11. Experimental Tesla coil resonance frequencies.

In Fig. 11 experimentally determined resonance frequency placement of a Tesla coil is shown. The amplitude is given in relative units because the accurate measurement of the voltage in the line and its terminals without changing its value is a problem. It is difficult because there is no such voltmeter that would have input capacitance $C_{i e}$ equal with 0 . Experiments show that Tesla coil working conditions are being influenced even by connection of $1 \mathrm{pF}$ capacitance. Output voltage value can be indirectly estimated by the length of electric spark at the output of the coil.

By comparing experimental AFR (Fig. 11) with theoretical (Fig. 8) it can be observed that they are close and are matching each other. A resonance network forms in Tesla coil. Theoretical distances between resonances $\Delta f=f_{n+1}-f_{n}$ should be equal (Fig. 8), but experimental measures indicate that with increasing frequency the distance $\Delta f$ slightly decreases (Fig. 11). It may be due to the fact that real line is not homogenous, and losses of electromagnetic energy while frequency is rising are increasing because the radiated wave length $\lambda_{E M}$ is closing to the dimensions of the coil. By increasing the losses the resonance frequency decreases, therefore decreases $\Delta f$.

Using the closest to the output of a coil voltage minimum coordinate $x_{0}$ for different resonances $\left(x_{10}, x_{20}, x_{30}\right)$, average wave length $\lambda_{n}=2 x_{n 0} / n$ and angle $\varphi_{i z}$ values for different resonances with not connected output capacitance $C_{s l}$ can be determined: $\lambda_{1}=2 \times 0.57 / 1=1.14 \mathrm{~m}-$ for a $3 \lambda / 4$ wave resonance;

$\lambda_{2}=2 \times 0.675 / 2=0.675 \mathrm{~m}-$ for a $5 \lambda / 4$ wave resonance; $\lambda_{3}=2 \times 0.725 / 3=0.483 \mathrm{~m}-$ for a $7 \lambda / 4$ wave resonance.

Formula (30) allows calculation of the angle:

$\varphi_{i z 1}=-17.4^{0}-$ for a $3 \lambda / 4$ wave resonance;

$\varphi_{i z 2}=-23.3^{0}-$ for a $5 \lambda / 4$ wave resonance;

$\varphi_{i z 3}=-34.1^{0}-$ for a $7 \lambda / 4$ wave resonance.

Knowing $\varphi_{i z 1}$ and using formulas (33) and (35) quarter wave resonance parameters can be calculated: $\varphi_{i z 0}=-6.3^{0}$ and $\lambda_{0}=4 \times 0.86=3.44 \mathrm{~m}$.

It must be admitted that the coordinates for higher resonances $x_{30}$ and $x_{30}$ are located close to the end of the coil, therefore their determination is associated with high measurement error. Measurement offset in bounds of one centimeter causes the change of $\varphi_{i z}$ value by more than 10 degrees.

Knowing average resonance wave lengths $\lambda_{0}$ and applying formula $\beta=2 \pi / \lambda$ allow calculation the corresponding average phase coefficients $\beta_{n}$ :

$\beta_{0}=18.3 \mathrm{rad} / \mathrm{m}$

$\beta_{1}=5.51 \mathrm{rad} / \mathrm{m}$;

$\beta_{2}=9.31 \mathrm{rad} / \mathrm{m}$;

$\beta_{3 v}=13.0 \mathrm{rad} / \mathrm{m}$.

Knowing average the coefficients $\beta_{n}$ allow calculating of product $L_{0} C_{0}=\beta_{n}^{2} / \omega_{n}^{2}$ for each resonance:

$L_{0} C_{0}^{\prime}=3.16 \times 10^{-14}, L_{0} C_{0}^{\prime \prime}=3.76 \times 10^{-14}$,

$L_{0} C_{0}^{\prime \prime \prime}=4.43 \times 10^{-14}, L_{0} C_{0}^{\prime \prime \prime \prime}=4.99 \times 10^{-14}$.

Then average capacitance per length unit is $C_{0}=L_{0} C_{0} / L_{0}$ :

$C_{0}^{\prime}=14.4 \mathrm{pF} / \mathrm{m}, C_{0}^{\prime \prime}=17.1 \mathrm{pF} / \mathrm{m}$,

$C_{0}^{\prime \prime \prime}=20.2 \mathrm{pF} / \mathrm{m}, C_{0}^{\prime \prime \prime \prime}=22.7 \mathrm{pF} / \mathrm{m}$.

Average characteristic impedance $Z_{C}=\sqrt{L_{0} / C_{0}}$

$Z_{C}^{\prime}=12.4 \mathrm{k} \Omega, Z_{C}^{\prime \prime}=11.3 \mathrm{k} \Omega$,

$Z_{C}^{\prime \prime \prime}=10.4 \mathrm{k} \Omega, Z_{C}^{\prime \prime \prime \prime}=9.85 \mathrm{k} \Omega$. 
By viewing the obtained data it can be noticed that the average capacitance per length unit $C_{0}$ by rising frequency is increasing by approximately $35 \%$ and $Z_{C}$ is decreasing by approximately $20 \%$, although these values should be constant. It might be explained with heterogeneity of the line.

To obtain the idle-load output capacitance $C_{i z 0}$ and local characteristic impedance in reflection zone $Z_{C i z}$ it is necessary to obtain together with idle-load resonance frequencies $\omega$ and output angles $\varphi_{i z}$ the same parameters for the known load capacitance. The obtained results have to be processed using formula (32) and the equation system for idle-load and loaded cases have to be solved.

$$
\left\{\begin{array}{l}
C_{i z 0} Z_{C i z}=\frac{\left|\tan \left(-\varphi_{i z 1}\right)\right|}{\omega_{1}} \\
\left(C_{i z 0}+C_{s l}\right) Z_{C i z}=\frac{\left|\tan \left(-\varphi_{i z 2}\right)\right|}{\omega_{2}} .
\end{array}\right.
$$

By solving equation (36) characteristic impedance at the reflection zone

$$
Z_{C i z}=\frac{\omega_{2} \tan \left(\varphi_{i z 1}\right)-\omega_{1} \tan \left(\varphi_{i z 2}\right)}{C_{s l} \omega_{1} \omega_{2}}
$$

and idle-load output capacitance are obtained

$$
C_{i z 0}=\frac{C_{s l} \omega_{2} \tan \left(\varphi_{i z 1}\right)}{\omega_{1} \tan \left(\varphi_{i z 2}\right)-\omega_{2} \tan \left(\varphi_{i z 1}\right)} .
$$

By inserting into the equations (37) and (38) respective, from Table I, and $\varphi_{i z}$, from (30), values the following results are obtained.

For resonance $3 \lambda / 4$ and for $39.4 \mathrm{~mm}$ sphere: $\varphi_{i z 1}=-17.4^{0}, \varphi_{i z 2}=-41.4^{0}, Z_{C i z}=10.4 \mathrm{k} \Omega, C_{i z 0}=1.06 \mathrm{pF}$. For resonance $3 \lambda / 4$ and for $65.0 \mathrm{~mm}$ sphere: $\varphi_{i z 1}=-17.4^{0}, \varphi_{i z 2}=-53.5^{0}, Z_{C i z}=11.9 \mathrm{k} \Omega, C_{i z 0}=0.93 \mathrm{pF}$. For resonance $5 \lambda / 4$ and for $39.4 \mathrm{~mm}$ sphere: $\varphi_{i z 1}=-23.3^{0}, \varphi_{i z 2}=-58.2^{0}, Z_{C i z}=13.2 \mathrm{k} \Omega, C_{i z 0}=0.74 \mathrm{pF}$. For resonance $5 \lambda / 4$ and for $65.0 \mathrm{~mm}$ sphere: $\varphi_{i z 1}=-23.3^{0}, \varphi_{i z 2}=-73.5^{0}, Z_{C i z}=20.3 \mathrm{k} \Omega, C_{i z 0}=0.48 \mathrm{pF}$.

Differences between the calculated results $Z_{C i z}$ and $C_{i z 0}$, which are obtained for both resonances, can be observed. The resonance data should be considered more correct because of the increasing measurement errors for higher order waves.

\section{CONCLUSION}

The following is concluded: 1) Tesla coil can be considered as one-wire electrical system; 2) Tesla coil is a long line with distributed parameters that as a common wire has a virtual ground; 3) At particular frequencies electrical resonances with different spatial configurations form in a coil; 4) Resonance processes in Tesla coil can be theoretically described using traditional theory of a long line; 5) Existence of resonance networks in Tesla coils is approved experimentally; 6) The obtained experimental results comply with theoretically calculated values; 7) The obtained mathematical single wire line results can also be applied to a traditional two wire long line; 8) Parameters Tesla coil $L_{0}, C_{0}, \beta$ and $Z_{C}$ depend on the length of coordinate $x$; 9 ) It is better to calculate Tesla coil base parameters from lower resonances due to lower measurement errors.

\section{REFERENCES}

[1] I. Dūmiņš, K. Tabaks, J. Briedis u. c. Elektrotehnikas teorētiskie pamati. Stacionāri procesi lineārās ḳēdēs, I. Dūmiṇa redakcija. Rīga: Zvaigzne ABC, 1999. 301 lpp.

[2] M. Tilbury, The Ultimate Tesla Coil Design and Construction Guide, McGraw-Hill, 2008. [Online]. Available: http://issuu.com/theresistance/ docs/-np--the-ultimate-tesla-coil-desig_20101219_062111

[3] M. Denicolai, Tesla Transformer for Experimentation and Research. http://www.saunalahti.fi/dncmrc1/lthesis.pdf

[4] J. Voitkāns, J. Greivulis, Elektriskās enerǵijas pārvadīšanas iespējas pa vienvada līniju. II Pasaules latviešu zinātnieku kongress. Tēžu krājums, Rīga, 2001, 263 lpp.

[5] J. Voitkāns, J. Greivulis, Vienvada elektropārvades līnijas eksperimentālās iekārtas tehniskie raksturojumi. Zinātniskā konference „Elektroenerǵêtika tehnologiijas”. Tēžu krājums, Kauņa, 2003.

[6] J. Voitkans, J. Greivulis and A. Locmelis, "Single wire transmission line of electrical energy", EPE - PEMC scientific conference, Riga, 2004.

[7] J. Voitkāns, J. Greivulis and A. Voitkāns, "Single Wire and Respective Double Wire Scheme Equivalence Principle."7th International Scientific Conference ,Engineering for Rural development”, Jelgava, 2008.

[8] J. Voitkāns, S. Voitkāns, A. Voitkāns. LV patents Nr. 13785 "Elektriski vadoša ķermen,a paškapacitātes mērītājs", "Patenti un preču zīmes", 2008. Nr. 10.

[9] I. Dūmiņš Elektrotehnikas teorētiskie pamati. Pārejas procesi, garās līnijas, nelineārās k̦ēdes., Zvaigzne ABC, Rīgā, 2006.

[10] J. Voitkāns, A. Voitkāns and I. Osmanis, "Investigations on Electrical Fields and Current Flow through Electrode System within Electrode”. 8th International Scientific Conference „Engineering for Rural development”, Jelgava, 2009.

[11] J. Voitkāns, J. Greivulis. LV patents Nr. 13432 "Sinusoidāla sprieguma pārvades vienvada linnija". "Patenti un preču zīmes", 2006. Nr. 6.

[12] J. Voitkans, J. Greivulis. "Loading aspects of a single wire electric energy transmission line, "International scientific conference "Advanced Technologies for Energy Production and Effective Utilization”. Jelgava, 2004.

[13] J. Voitkāns, J. Greivulis. LV patents Nr. 12932 "Vienvada regulējamā elektropārvades līnija". "Patenti un preču zīmes", 2002. Nr. 12.

[14] J. Voitkāns, J. Greivulis. LV patents Nr. 13031 "Simetrizēta vienvada elektropārvades līnija". "Patenti un preču zīmes", 2003. Nr. 7.

[15] B. B. Anderson, The Clasic Tesla Coil, 2000. [Online]. Available: http://www.tb3.com/tesla/tcoperation.pdf

[16] G. L. Johnson, Solid State Tesla Coil. 2001. [Online]. Available: http://hotstreamer.deanostoybox.com/TeslaCoils/OtherPapers/GaryJohns on/tcchap1.pdf

[17] G. F. Haller and E. T. Cunningham, The Tesla High Frequency Coil. New York, 1910.

Janis Voitkans graduated from Riga Polytechnical Institute in 1976 as a radio-engineer. He received Dr. sc. ing. in electrical engineering at Riga Technical University, Riga, Latvia, in 2007. His research interests are connected with electro physics and power electronics.

$\mathrm{He}$ is presently a Senior Researcher with the Institute of Industrial Electronics and Electrical Engineering, Riga Technical University

Address: Āzenes 12, Riga, Latvia;

E-mail: janis.voitkans@rtu.lv

Arnis Voitkans received $B . S c$ and $M . S c$. in physics at the University of Latvia, Riga, Latvia in 2003 and 2006, respectively. Currently he is a leading systems analyst with the IT Department of the University of Latvia.

Address: Aspazijas Boulevard 5, Riga, Latvia;

E-mail: arnis.voitkans@lu.lv 